\title{
Hellen ve Roma Dünyasında Patronus-Cliens İlişkisi
}

\author{
Dr. Öğr. Üyesi Ümran Ozan Karahan \\ Uşak Üniversitesi, Fen-Edebiyat Fakültesi \\ Tarih Bölümü \\ ozan.karahan@usak.edu.tr
}

\begin{abstract}
Öz
Patronus-cliens ilişkisinin kökeni Roma'nın kurucusu olarak bilinen Romulus'a kadar dayandırılmaktadır. Roma dünyasında kimi zaman bireyler kimi zaman topluluklar güçlü nüfuza sahip kişiler tarafından korunma ihtiyacı hissetmişlerdir. Bunun yanı sıra kentler, Roma senatusuna erişim sağlayabilmek için en hizlı ve etkin bir yöntem olarak bu sisteme dâhil olmuşlardır. Kentler, senatusta kendi istek ve şikâyetlerini etkili bir şekilde dile getirsinler diye bir hamiye ihtiyaç duymuşlardır. Bazen kentlere Romalı yöneticiler, ağır yükümlülükler yüklemekteydiler. Bu nedenle bu ağır yükümlülüklere maruz kalmamak için yöneticilerin yanaşması olmayı tercih etmişlerdir. Kent konseyinin talebi doğrultusunda hami olarak senatusta etkili olabilecek bir isim seçilmekteydi. Seçilen elçilerin aracıllğıyla bu talep hamiye iletilirdi. Talep karşılık görürse hami-yanaşma ilişkisi başlardı. Hami-yanaşma ilişkisinde karşılıklı yükümlülükler yer almaktaydı. Bu ilişki gayri resmi bir ilişki olduğu için hukuki bir yaptırım söz konusu değildi. Senatörler için hami-yanaşma ilişkisi itibar meselesiydi. Karşılıklı menfaat ilişkisine dayanan himaye sistemi Roma'nın geniş topraklarında yaygın olarak görülmekteydi. Antik kaynaklar, onurlandırma yazıtları ve tabulae patronatuslar bu sistem hakkında ayrıntılı bilgiler vermektedir. Batı Anadolu'da yer alan çok sayıda kent kendisine çeşitli nedenlerle hami ya da hamiler seçmiştir. Kimi zaman halka karşı iyi niyet beklentilerinin karşılanması için kimi zaman da yöneticinin verebileceği zararlardan korunmak için önemli isimleri kendilerine hami olarak seçmişlerdir. Biz de bu çalışmamızda Hellen ve Roma dünyasında bulunan olgulardan biri olan patronus-cliens kavramları hakkında, epigrafik, antik ve modern kaynaklara dayanarak değerlendirmede bulunmaya çalışacă̆ız.
\end{abstract}

Anahtar Kelimeler: Hami, yanaşma, senatus, tabulae patronatus.

\section{Patronus-Cliens Relationship in Hellen and Roman World}

\section{Abstract}

The origin of the patronus-cliens relationship go back to Romulus, who is known as the founder of Rome. In the Roman world, sometimes individuals felt the need to be protected by people with strong influence. In addition, the cities were included in this system as the fastest and most effective method to access the Roman Senate. The cities needed a patronus so that they could express their wishes and complaints effectively. Sometimes Roman rulers imposed heavy obligations on the cities. For this reason, they preferred to be the cliens of the 
managers in order not to be exposed to these heavy obligations. This request would be forwarded through the chosen delegates. If the demand was met, the patronus-cliens relationship would start. Mutual obligations were involved in the patronus-cliens relationship. As this relationship was an informal one, there was no legal sanction. For the senators, the patronus-cliens relationship was a matter of reputation. The patronage system based on mutual interests was widespread in the vast territories of Rome. Ancient sources, honorary inscriptions and tabulae patronatus provide detailed information about this system. Numerous cities in Western Anatolia have chosen a patronus or more than one patronus for themselves for various reasons. They have chosen important names as their patronus, sometimes in order to meet their expectations of goodwill against the people, and sometimes to protect them from the damages that the ruler can cause. In this study, we will try to evaluate the concepts of patronus-cliens, one of the facts in the world of Hellenistic and Roman, based on epigraphic, ancient and modern sources.

Keywords: Patronus, cliens, senatus, tabulae patronatus. 


\section{GİRIŞ}

Patronus-cliens ilişkisi Roma tarihinin en karakteristik özelliklerinden biridir. Kuruluşundan geç antik döneme ve hatta ötesine kadar giden bir sistemdir. Bir biçimde Roma'nın kuruluşundan itibaren başlamış ve çöküşüne kadar devam etmiştir. Tarihçiler arasında kökeni konusunda fikir birliği olmasa da Romulus'tan itibaren görülmeye başlandığı ve Iustinianus dönemine kadar sürdüğü iddia edilmektedir (Badian, 1967, s. 2; Eilers, 2002, s. 1; Deniaux, 2006, s. 401).

Bu sistem, patronus (hami) ile cliens (yanaşma) ilişkisinden doğmaktadır. Şu şekilde de tanımlanmaktadır: "Yüksek sosyo-ekonomik statüden bir bireyin (patronus=hami) mülkiyet velveya denetimindeki kaynakları ve etkisini, karşılığında kendisine kişisel hizmetler de dâhil olmak üzere genel destek ve yardım să̆layacak daha dü̧̈ük sosyo-ekonomik statüden bir bireye (cliens=yanaşma) koruma velveya yarar sağlamak üzere kullandığı büyük ölçüde araçsal bir arkadaşlığı içeren ikili bağların bütünüdür" (Emiroğlu-Aydın, 2003, s. 479).

Patronusun tanımını yapmak çok kolay değildir. Örneğin patrocinium, patronatus fides ve clientela gibi terimler aynı olgunun farklı yönlerini tarif etmektedir (Nicols, 1980, s. 365). Latince kökenli olan Patronus, farklı şekillerde tanımlanabilmektedir. Latincede patrocinium patronluk yapma, koruma anlamina gelirken, patronus ise patron (yani hami) anlamina gelmektedir. Latincede cliens/entis yanaşma, clientela ise yanaşma durumunda olan demektir (Akderin, 2018, s. 105; s. 401). Aslında İngilizce'de yer alan "patronage" teriminin, bu terimlerin tanımladığı kurumlar için yeterli olup olmadığı da zor bir sorudur. "Patronage" terimi genellikle yapılacak yardımların, iyiliklerin ve atamaların güçlü nüfuza ve statüye sahip kişiler tarafından yapılması anlamına gelmektedir (Nicols, 1980, s. 365-366; Finley, 1983, s. 39-47; Johnson\&Dandeker, 1990, s. 221-224; Eilers, 2002, s. 3). Cliens terimi ise kendilerini patronusun güvenine ve himayesine adayanlar anlamındadır. Dolayısiyla bağlılıklarını bildiren taraf olarak tanımlanmaktadır (Eilers, 2002, s. 19).

\section{Patronus-Cliens İlişkisi}

Clientelae terimine tabulae patronatuslarda (himaye-yanaşma kayıtlarının yer aldığ1 bronz levhalar) da rastlanılmaktadır. Hem hami hem de yanaşma halklar patrocinium gerçeğine atıfta bulunurlarken, clientelae terimine nadiren de olsa atıfta bulunmaktadırlar. Tabulae patronatuslardaki örneklerden hami ile yanaşma durumunda olan halklar arasındaki sözleşmelerin (yani himaye/hamilik sözleşmeleri) oldukça özel oldukları anlaşılmaktadır. Bir kişinin bir kent tarafından hami olarak seçilebilmesi için kent kararnamesi (decretum decurionum) ile resmen kabul edilmiş olması gerekmektedir (Nicols, 1989, s. 117-142; 2014, s. 4).

Hami ve yanaşma ilişkisi (yani himaye ilişkisi), eşit statüye ve kaynaklara sahip olmayan kişilerin ya da toplulukların arasında karşılıklı, sürekli ve genelde resmi olmayan ahlaki temelli bir ilişkidir. Yani ilişki bir tür mal ve/veya hizmet alışverişinde yer alan tarafların arasında gerçekleşmektedir. Hami ve yanaşmanın aynı statüye ve kaynağa sahip olmaları gerekmemektedir. Hami yanaşmasına gerekli olduğu durumlarda danışmanlık yapmaktadır. Gerektiğinde ise haklarını korumaktadır. Hami ile yanaşma arasındaki ilişki yasal bir eylemde olmakla beraber Roma kanunları dışında tutulmuştur. Yani hami ile yanaşma arasında bir anlaşmazlık yaşandığında mahkemede bir hak iddia edememektedirler. Aslında bu ilişki özel bir ilişki de değildir. Çünkü hamilerin pek çok yanaşması olabilmekteydi (Badian, 1967, s. 62; Saller, 1982, s. 8-11; Herman, 1987, s. 39;

SEFAD, 2020; (44): 527-546 
Wallace Hadrill, 1990, s. 68-69; Rich, 1990, s. 118-126; Garnsey\&Woolf, 1990, s. 153-154; Deniaux, 2006, s. 404; Nicols, 2014, s. 2-18).

Ahlâki yükümlülüklere dayanan gayri resmi bir ilişki olan himayede, yükümlülükleri ihlal etmenin yaptırımları hukuki değil, ahlaki ve sosyal yaptırımlardır. Eşit muamele sağlamaktan uzak olan himaye sistemi, yanaşmaya benzer durumlarda diğer kişilere ya da toplumlara karşı avantaj sağlamaktadır. Kıt kaynakların/imkânların herkes tarafından elde edilememesi durumunda, birkaç kişinin onlara ayrıcalıklı erişim sağlamasının bir yoludur (Gelzer, 1969, s. 100-102; Westbrook, 2005, s. 211-212).

Hamileri birincil derecede egemen yönetici konumunda olanlar ve yüksek devlet görevlilerine erişimi olan asil kişi veya görevlilerden oluşan aracı hamiler olarak ayırabiliriz. Şunu da belirtmek gerekir ki senatusa erişimin sağlanması konusunda hamilerin kesin başarı sağlayacağ 1 düşünülmemelidir. Tarafların üzerlerine düşen yükümlülükleri yerine getirmeleri kendilerine saygınlık ve nüfuz kazandırmaktadır. Uzun vadeli bu ilişkide aralarında anlaşmazlıkların yaşanması durumunda bu anlaşmazlığı hukuki sürece taşıma imkânları yoktur. Çoğunlukla taraflar yükümlülüklerini yerine getirmelerini sağlamak için kutsal ifadeler ve ahlaki yaptırımları kullanmak durumunda kalmışlardır (Tac. Hist. 1. 2-3; Bloy, 2012, s. 201; Nicols, 2014, s. 2-3).

Hami-yanaşma ilişkisi çeşitli şekillerde görülebilmektedir. İlk olarak kişisel himaye sistemi olarak görülmektedir. Statü olarak önemli bir konumda olan kişinin düşük statüde bulunan bir kişiyi yanaşma olarak kabul etmesidir. Bu kategori genellikle Roma hukuku kapsamı dişında kalmıştır. Bir diğer kişisel himaye şekli, hami ile eski (azatlı) kölesi (libertus) arasında sadakata dayanan bir ilişkidir. Bu ilişkiye önem verdikleri için Roma hukukunda ayrıca düzenlenmiştir. Bu nedenle ayrı bir başlık altında yer almıştır. Üçüncü olarak da savunucunun (orator-hatip/patronus causae) edindiği himaye olarak görülmektedir. Özellikle müvekkili ile ilgili olarak önceki hizmetleri karşıllğıında ücretsiz bir şekilde verilmiş olan himayedir. Son olarak ise toplulukların yani kentlerin himayesidir (Nicols, 2014, s. 3). Ayrıca Eilers, Roma'daki önemli şair ve düşünürlerin aristokratlar tarafından desteklendiğini, bu nedenle bu tür uygulamaların da koruyucu bir hamilik olarak antik çağda görüldüğünü belirtmektedir (Eilers, 2002, s. 2-3).

Himaye kişisel bir ilişkidir ve sıklıkla dostluk üzerine kurgulanmıştır. Statü olarak eşitlik söz konusu olmayan bu ilişki içerisinde maddi olmayan hizmetler yer almaktadır. Yanaşma böylece karar organlarında veya senatus içinde etkin olan kişilere erişimi sağlamaktadır. Yanaşmanın hamisine maddi olmayan en büyük hizmeti ise sadakattir. Hami mal ve/veya hizmetlerden aldığından daha fazlasını veriyor gibi görünse de, aslında haminin bu ilişkilerden dolayı sağladığı itibar çok daha önemlidir. Tek seferlik bir yardım ya da ayrıcalık himaye olarak kabul edilmemektedir. Bu ilişkinin gönüllülük esasına dayanması gerekmektedir (Westbrook, 2005, s. 211).

\section{Hellen ve Roma Toplumlarında Patronus-Cliens İlişkisi}

Roma'da bir pleb (halk, avam) tabakasından biri patrici (soylu) sınıfından birinin himayesi altına girebiliyordu. Böylece Pleb, patricinin yanaşması olunca hamisine, siyasi ve gerektiğinde de askeri hizmet vermek zorundaydı. Hami ise bu hizmetin karşılığında, sahip olduğu her bir yanaşma ile itibarını artırır ve yanaşmasına bazen para vererek, bazen anlaşmazlıkların çözümü için ve bazen de yasal sorunları olduğunda onları desteklerdi. Yasal dayanağı bulunmamakla beraber karşılıklı faydaya dayanan ve çok saygı duyulan bu 
ilişki nadiren bozulurdu. Bir Romalı eşini terk edebilir hatta oyunu en çok para verene satabilirdi ama hami-yanaşma ilişkisini kutsal olarak kabul etmekteydi (Freeman, 2019, s. 12).

M.Ö. 172 yılında Rhodoslu elçiler Pergamon Kralı II. Eumenes'in aracıllğıyla senatus ile doğrudan konuşabilmek için, Roma' daki hamileri diyebileceğimiz per patronos hospitesque (gönüllü elçi/fahri konsolos) yoluyla çaba gösterdikleri bilinmektedir. Hızlı bir şekilde senatusa kabul edilebilmek için siyasi müttefiklerin etkisinin gerekli olduğunu belirtmek gerekir. Şunu da ifade etmek gerekir ki o dönemde senatusta yabancı elçilerin kendi dillerinde konuşma yapmaları yasaklanmıştır. Hatta Valerius Maximus sadece Roma'da değil, Yunanistan ve Küçük Asia'da da bir tercüman aracilığıyla konuşmak zorunda olduklarını ifade eder (Val. Max. 2.2). Bu durumda da Latince bilen seçkin kişilere ihtiyaç duymuşlardır. Dolayısıyla Romalı senatörler himaye terimini henüz kullanmadan önce muhtemelen kentlerle bu tür ilişki içerisinde bulunmaktaydılar (Liv. 42. 14; Eilers, 2002, s. 109-111; Bloy, 2012, s. 174-175).

Bir diğer örnek M.Ö. 168 yılında gerçekleşmiştir. Roma'da bulunan Pergamon Kralı II. Eumenes'in kardeşi Attalos'a Romalı senatörler II. Eumenes'in yerine kral olması teklifinde bulunmuşlardır. Senatus bu teşebbüsü desteklemiştir. Bunun sonucunda Attalos hamisi denilebilecek bazı etkili adamlar ve senatörler ile kardeşi II. Eumenes'in yerine kral olmak için bir anlaşma yapmıştır. Ancak Kral II. Eumenes bu entrikayı doktoru aracilığıyla bozmuştur (Polyb. 30. 1-3). Başka bir örnek ise Kappadokia ile ilgilidir. Soter I. Demetrios'un döneminde elçileri (hamileri denilebilir) Kappadokia' da hak iddia eden sahtekâr Orophenes aleyhinde, Kappadokia kralı V. Ariarathes'in lehinde Roma senatusunda özel bir konuşma yapmışlardır (Polyb. 32.10.2; 32.10.5; Gelzer, 1969, s. 91).

Bu toplantılar için senatusun profesyonel tercüman kadrosunun olması muhtemeldir. Ancak elçilerin senatustaki isteklerinin, senatusun önde gelen bir üyesi tarafından dile getirilmesi daha makbuldü. M.Ö. II. yüzyılda bu usule ilişkin bir uygulama kanıt olabilecek ölçüdedir. M.Ö. 155 yılında Atinalılar üç filozofu ikna edici konuşmaları için elçi olarak göndermişlerdir. Ancak elçilerin bahsedecekleri konular hakkında onlardan daha önce senatus üyesi olan C. Acilius senatusta konuşmuştur (Plut. Cato. 22; Cic. Att. 1. 12). Bu nedenle senatörlerin yanaşmaları için tercümanlık yaptıkları anlaşılmaktadır. M.Ö. II. yüzyılın başlarında senatör hamiler, Hellen dünyası ile Roma arasındaki iletişimi sağlama açısından etkin bir rol oynamışlardır. Nitekim Makedonya Kralı V. Philippos ile yapılan görüşmelerin ardından T. Quinctius Flamininus ateşkes için elçilerin gönderilmesini kararlaştırmıştır (Polyb. 18.11.1-2; Rich, 1990, s. 128; Bloy, 2012, s. 175-176).

Patron ve patroneia terimleri Hellen yazıtlarında M.Ö. II. yüzyıldan itibaren görülmeye başlanmıştır. Makedonya'da Akhaların bir bölümünde ve sonra Asia Eyaleti'nde görülmeye başlayan bu terimler zamanla büyük ölçüde artmıştır. Özgür kentler dahi Roma senatusunda olabilecek davalarında, bir hamiye ihtiyaç duymuşlardır. Bu durumu ünlü Ion kenti Teos'un Abdera ile ilgili kararından (Syll. 656; Sherk 26; Polyb 30.17; Liv. 45. 42) bilmekteyiz. Teos'un kolonisi Abdera'nın aracılık yapan hamileri bulunmaktaydı. Trakya Kralı Kotys, Abdera ile ilgili bölge mülkiyeti hakkında açtığı davada senatusta hakemlik yapmak için gerekli bir hamiye ihtiyaç duymuştur (Hdt. 1. 168; IG XII/6. 351; Eilers, C51; Gelzer, 1969, s. 89; Herrmann, 1974, s. 257-258; Braund, 1990, s. 137-138; Ferrary, 1997, s. 106-107; Bloy, 2012, s. 192-193).

SEFAD, 2020; (44): 527-546 
M.S. II. yüzyılın son yıllarına, MÖ 120 'lere tarihlendirilen bir başka yazıt Samos Heraion'unda bulunmuştur. Patron terimini içeren bu yazıt bir Romalıyı onurlandıran Samosluların hamisi olan, babası ile aynı adı taşıyan C. Domitius Ahenobarbus'un heykelinde yer almaktadır. Artemis Tauropolis Tapınağı ile ilgili meselede senatus tarafından halkın savunucusu olarak görev yapan Gnaeus'un oğlu Gnaeus Domitius'a ithaf edilen heykelde bu terim geçmektedir (IG XII/6. 351; Eilers, C51; Eilers, 2002, s. 121-124; Bloy, 2012, s. 186).

Yazıtta bahsedilen hami, yani onurlandırılan Romalı C. Domitius Ahenobarbus M.Ö. 129 ile 126 yıllarında Asia Eyaleti'nde legatusluk (elçi) yapmıştır. M.Ö. 122 yılında da consul seçilmiştir. Samos'u da ilgilendiren bazı yasal işlerle ilgilenmiştir. Eilers bu onurlandırmanın nedenini, M.Ö. 123/122'deki Gracchus reformundan daha önce tekrarlanan bir de repetundis (gasp) davası olabileceğini öne sürmektedir. Başka bir olasılık ise Samos ile Roma arasında Artemis Tauropolos Tapınağı'nın üzerinde kentin hakları ilgili olarak bir çatışma olabileceğidir. Her durumda Roma senatusunun Hellenistik dünya üzerinde bir hamilik dayatması olarak algılanabilecek bu dava, Samosluların Roma'nın yasal işlemlerinin zorluklarıyla başa çıkabilmek için açıkça bir hamiye ihtiyaç duyduklarının göstergesidir (Eilers, 1991, s. 167-178; Ferray, 1997, s. 106-107).

Hellenistik dünyada kentlerin hayırseverleri ya da koruyucuları anlamına gelen pek çok terim kullanılmıştır. Euergetes, benefactor, soter, kedemon ve proxenos gibi. Esasen benefactor ve euergetes terimleri hami unvanlarından farklıdır. Bunlar tek taraflı bir ilişkinin göstergesi olan tariflerdir. $\mathrm{Bu}$ terimler kral gibi büyük bir güce sahip olan kişiler ya da topluma faydaları olan seçkin kişilerin onurlandırılması için kullanılmıştır. Bu onurlandırmalar genelde taç ve heykel gibi ödülleri içermekteydi (Bowersock, 1965, s. 13; Gelzer, 1969, s. 88; Ferrary, 1997, s. 105-106; Eilers, 2002, s. 110; Bloy, 2012, s. 168-182).

Hellence yazitlarda patron terimi kullanılmadan önce bile kentlerin hamilerinin olduğu kullandıkları proxenia ${ }^{1}$ teriminden anlaşılmaktadır. M.Ö. 189/188 yıllarında Delphoi Kenti, T. Quinctius, L. Acilius ve M. Aemilius Lepidus'a proksenos unvanı vermiştir. Bu üç isim tarih belirtilmemiş olan proxenoi listesinde yer almaktadır. Ancak M. Aemilius Lepidus'un onuruna verilen kararname neyse ki korunmuş durumdadır. Bu hamilerin senatustan Delphoi kentine ve tapınağına özerklik verilmesinde yardımcı oldukları bilinmektedir. M.Ö. 82 yılına ait bir Rhodos yazıtında Lucius Cornelius (Sulla), Lucius Cornelius Lentulus, Lucius Licinius Murena, Lucius Licinius Lucullus ve Aulus Terentius Varro'ya proksenos ve euergetes unvanlarının verildiği anlaşılmaktadır (Syll 585; Syll 745). Patronus ile proxenia arasındaki temel fark, patronus yani hamilik sadece kent tarafından verilen bir onur değildir. Aynı zamanda Roma aristokratlarına bir bağlılıktır. Fakat proxenia gerçek bir bağlılık değildi. O sadece ayrıcalıklı bir statüydü. Bir kentin iyi niyet göstergesi olarak bu ilişkiye sadık kalması için bir yabancının ödüllendirilmesinden ibaretti (Ferrary, 1997, s. 108-109; Bloy, 2012, s. 177-183).

Eski Hellen Kurumu olan proxenia zamanla Hellenler tarafından da kabul edilen patronatus terimine dönüşmüştür. Cumhuriyetin sonuna kadar bu tür ilişkiler devam etmiştir. Kimi zaman zulme uğrayan kentin talebi üzerine senatus tarafında da hami ataması

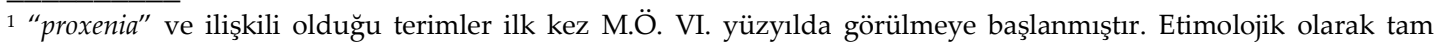
anlamı bilinmemekle beraber, "fahri konsolos" anlamında kullanılabilmektedir. Yani vatandaşı olduğu kent devleti içinde diğer kent devletlerinin çıkarını gözeten ve proksenos diye adlandırılan diplomatik araç için kullanılan bir terimdir. Bkz. Wallace, 1970, s. 189-208; Pomeroy, 2018, s. 392.
} 
yapılmaktaydı. Suçlamaya maruz kalan valiler hakkında kovuşturma yapmak için atamalar yapılabiliyordu. Hispania Ulterior'da, yabancı kentlerin ve halkların büyük asil aileleri kendi çıkarlarını koruyabilmek için Caesar ile bu tür ilişkiye girmek zorunda kalmışlardır. Yasa önünde bir bağlayıcılığı olmayan bu ilişkide haminin başlıca görevi Roma ile yanaşma devleti arasındaki diplomatik ilişkileri kolaylaştırmaktı (Badian, 1967, s. 159-161; Braund, 1990, s. 138-139).

Hami, Roma'ya giden himayesindeki kentin elçilerini ağırlar ve onların preatorlar yoluyla senatus veya consul ile irtibat kurmalarını sağlardı. Ayrıca senatusta görülecek olan tahkim² gibi davaları hamileri olmadan kazanmaları zordu. Bu nedenle kentlerin senatus üzerinde bilgi ve etkiye sahip kişilere ihtiyaç duyması normaldi. Haminin bir diğer görevi de yanaşma olan kenti haraç ve baskıdan korumaktı. Görüldüğü gibi haminin yanaşma için yapabileceği şeyler çoktu. Doğal olarak karşılığında yanaşması olan kentten de bazı beklentileri olmaktaydı (Gelzer, 1969,s. 87-89; Nicols, 1990b, s. 101-102; Bloy, 2012, s. 174).

Geç Cumhuriyet döneminde hem Hellenler hem Romalılar Hellence olarak prostates ve euergetes terimlerini kullanmaya başlamışlardır. Tam olarak tanımlanamamış olmasına rağmen Hellenler Romalı bir haminin ne anlam ifade ettiğini bilmektedirler. M.Ö. 89- 31 yılları arasına ait, kentlerin Romalı hamilerinin olduğunu gösteren çok sayıda yazıt bulunmaktadır. Aynı döneme ait Latince yazıtların sayısı çok azdır. Yazıtlarda kullanılan patron ifadesi bazen tek başına kullanılırken, bazen yukarıda ifade etiğimiz gibi benzer ifadeler ile birlikte kullanılmaktadır. Bu yazıtlar karakteristik olarak onurlandırılan kişilerin unvanlarını içerir. Onurlandırmayı hak etmeleri için yaptıkları şeyler hakkında oldukça bilgilendiricidir. Coğrafi olarak yazıtların büyük çoğunluğu Roma ile yoğun ve uzun temasta olan bölgelere, Yunanistan ana karasına, Ege Adalarına ve Batı Anadolu'ya aittir. Devletin doğudaki hamilik sistemi örnekleri ile batıdaki hamilik sistemi örnekleri arasında bazen benzerlikler olsa da bazen de çarpıcı farklılıklar görülmektedir (Nicols, 1990a, s. 81-82; 2014, s. 70-71).

Kentlerin himayesinde hami olan taraf, genelde bireylerden oluşmaktadır. Yanaşma olan taraf ise halklardan meydan gelmektedir. Bazen her iki tarafın da halk olduğu ya da nadiren de olsa halkın hami olduğu, yanaşmanın ise birey olduğu örnekler de vardır. Hami ile yanaşma arasında eşit statü olmamasına rağmen bazen halkın imkânları birey olan haminin imkânlarından (genelde atlı sınıfın bir üyesi ya da komutan oluyorlardı) daha iyi olabiliyordu (Nicols, 2014, s. 16-18).

Romalılar, cumhuriyetin sonlarına doğru resmi bir ilişki olmasa da en azından gayri resmi olarak haminin ya da yanaşmanın statüsünü belirlemeye çalışmışlardır. Resmi bir ilişkiye dönüştüğünde ise haminin ve yanaşmanın nasıl davranması gerektiği belirlenmiştir. Kent himayesi, Roma'nın uyguladığı patrocinium publicum ile benzerdir. Yani doğuda Hellence konuşan kentlerin kamu yararına uyguladıkları sistem euergeteia ile Latince'de bulunan patrocinium publicum pratiği arasında ortak özellikler vardır. Ancak bunun kökeni Hellenistik Dönemin mirası olarak görülebilmektedir. Resmileştirilen kent himayesi sisteminde gelecek nesilleri de dâhil etmek için "sürekli" tabiri tanımlarda kullanılmaktadır. Nesiller boyu bu ilişkilerin devam edip etmediğini doğrulamak zordur. Ancak bazı yazıtlarda "atalardan kalma hamilik" (yani miras yoluyla) tabiri kullanılmaktadır. Bu

$\overline{2}$ Hellen kentlerinde tahkim için bkz. Karahan, 2019, s. 963-981. 
durum en azından hamiliğin babadan oğula ya da toruna aktarıldığını göstermektedir (Ferrary, 1997, s. 110-112).

Söz gelimi Stratonikeia kentinde Augustus'un son yıllarında Küçük Asia'da proconsullük yapmış olan L. Calpurnius Piso'yu onurlandırdığı bir yazıtta atalardan kalma hamilik tabirini görmekteyiz. Yazıtta; "Halk yeniden Lucius Calpurnius Piso'yu altın bir taç ve mermer bir heykelle taçlandırdı ve onurlandırdl, kentimizin hayırseveri ve atalarından kalma hamisi olarak" yazmaktadır (Tuchelt, 242; Eilers, C121). Ayrıca Knidos kentinin onurlandırdığı Nero Claudius Drussus yazıtında (Eilers, C114), Magnesia ad Spylum kentinin Potitus Valerius Messalla'yı onurlandırdığı yazıtta (Eilers, C103; Tuchelt, 185) ve yine Stratonikeia kenti tarafından M. Iunius Silanus adına yazdırılan onurlandırma yazıtında (Eilers, C124) bu tabire rastlanılmaktadır (Gregory, 1997, s. 85-91, Eilers, 1999, s. 77-86).

Kentlerin himayesi ile ilgili en net resmi belge Karia'daki Plarasa/Aphrodisias kentinden gelmektedir. M.Ö. 89/88'de VI. Mithridates Bithynia'yı işgal etmiştir. M. Aquillius'u yenerek Laodikeia'da Asia Eyaleti proconsulü olan Q. Oppius'u kuşatmıştır. Q. Oppius Roma'nın bölgedeki müttefiklerine yardım için başvurduğunda Plarasa/Aphrodisias hızla cevap vermiş ve birlikler göndermiştir. Ancak Q. Oppius yine de VI. Mithridates tarafından ele geçirilip tutuklanmıştır. Savaş sona erdikten sonra Q. Oppius serbest bırakılmıştır. Kos Adası'nda geçici bir süre kalmıştır. Bu dönemde Plarasa/Aphrodisiaslı elçiler kendisi ile görüşmek için Kos'a gitmişlerdir. Kendisinden kentlerinin hamisi olmasını talep etmişlerdir. Resmi yazışmalardan sonra hazırlanan Q. Oppius'un cevabı halka açık bir yere konulmuştur (Ferrary, 1997, s. 109-110; Eilers, 2002, s. 23).

M.S. II. yüzyıla tarihlenen yazıtta şöyle yazmaktadır:

“Romalılarm proconsulü, praetor, Quintus'un oğlu Quintius Oppius, magistratlara ve Plarasa/Aphrodisias konseyine ve halkına, selamlar gönderiyor.

...Adrastos'un? Oğlu Antipatros, Apollonios'un oğlu Pereitas, Myon'un oğlu Artemidoros, Menis'in oğlu Dionysios, Zenon'un oğlu Timokles, elçileriniz, nazik ve iyi insanlar, benimle Kos'ta buluştular. Beni tebrik ettiler ve benim varlı̆̆ımdan çok memnun olduğunuzu bildiren kararnameyi verdiler. Kesinlikle inandı̆̆ım gibi, bana ve halkıma karşı olan ilişkilerinizin iyi niyeti ışı̆̆ında; size Laodikeia'dan bana asker göndermeniz gerektiğini yazdığımda onlar ilk gönderenlerin arasındaydını. Roma halkının iyi müttefikleri ve arkadaşları olduğunuzu davranışlarınızla gösterdiniz. Ve gönderdiğiniz elçilerin iyi ve sinırsız faaliyetlerinden yararlandım. Bu nedenlerle ben hem magistrat olarak ve hem de özel bir birey olarak size ve halkınızın ilişkileri ile ilgili olarak iyi niyetimi korurken her zaman çıkarlarınızı korumak için elimden geleni yapacă̆ım ve ne zaman Roma'da bulunursam senatusa ve Roma halkına sizin yaptıklarınızı açıç̧a anlatacă̆ım. Aynı elçiler, size olan himayemin tadın çıkarmanıza izin vermem gerektiğ i ricasında bulundular. Kentinize olan saygım nedeniyle onları kabul ettim. Ve halkınızn hamisi pozisyonunu üstlendim" (Reynolds, 1982, s. 18; doc. 3).

Q. Oppius'un serbest kaldıktan sonra gittiği Kos, Mithridates Savaşları sırasında VI. Mithradates'in yanında yer almıştır. Hatta Rhodos'a saldırı için bir üs bile sağlamıştır. Daha sonra taraf değiştirmiştir. Ancak Roma'nın müdahalesinden kurtulamamıştır. Görünüşe göre Plarasa/Aphrodisias kenti hala etkili olduğunu düşündüğü Q. Oppius'u memnun etmek için çaba sarf etmiştir. Yazıttaki ifadeler elçilerin konuşmaları ve konseyin kararnamesinden oluşmaktadır. Q. Oppius'u, kentlerinin hamisi olması için ikna etme çabası içerisine girmişlerdir. Bunun için de kanıt olarak, Laodikeia'nın VI. Mithridates tarafından 
kuşatılması sırasında, Roma'yı desteklemek için hızlıca asker gönderdiklerini ve Roma'ya olan sadakatlerini gösterdiklerini öne sürmüşlerdir. Stratonikeia kentinin, Mithridates Savaşları'nda Roma'yı desteklemek için onlara sadık kalarak asker gönderdiğini, bundan dolayı Sulla'dan övgüler aldığını da bilmekteyiz (Sherk, 18). Kos ve Ephesos gibi kentler başlangıçta VI. Mithridates'i desteklemelerine rağmen, daha sonra Roma'nın tarafına dönerek bağlılıklarını bildirmişlerdir (Syll 682). Ancak Laodikeia kenti desteklere rağmen tek başına direnememiş ve teslim olmak zorunda kalmıştır. M.Ö. 85/84 kış aylarında Sulla Ephesos'taki ikametinden önce böyle bir ihtiyati karar almış olabileceği belirtilmektedir. Bu tarihlerde Roma'nın bir Hellen kentini yanaşma olarak kabul ettiğine dair başka bir bilgi yoktur (Reynolds, 1982, s. 18-20).

Görüldügü gibi Plarasa/Aphrodisias kenti Q. Oppius'a hamisi olması talebinde bulunmuştur. Bu kanıt himaye sistemi için önemlidir. Buradan anlaşılan bir konu da şudur $\mathrm{ki}$, nerede olursa olsun sisteme bakıldığında genellikle hamilik teklifi birkaç istisna dışında, yanaşmalardan gelmektedir. Söz konusu hamilik ilişkisinde haminin halka karşı ne gibi yükümlülüklerinin olduğuna dair bilgiler de vermektedir. Bu yükümlülükleri yerine getirirken diğer görevleri ile çatışmayacağına dair söz vermektedir. Kent, hamiliği kabul ettirebilmek için Roma'ya ve kendisine sadık kaldıklarını ve ne gibi hizmetlerde bulunduklarını dile getirmişlerdir (Ferrary, 1997, s. 109; Eilers, 2002, s. 24-25; Deniaux, 2006, s. 406-407; Bloy, 2012, s. 171; Nicols, 2014, s. 71-72).

Plarasa/Aphrodisiaslı elçilerin Q. Oppius'tan hamilik talebinde bulunmaları sürpriz olmamalıdır. Bu hamilik talepleri, başka örneklerden de anlaşıldığına göre normal bir uygulamaydı. Söz gelimi Genç Plinius'a da İtalya'nın Tifernum Tiberinum kentinden gelen elçiler böyle bir talepte bulunmuştur. Plinius da onlardan gelen bu isteği yerine getirmiştir. Plinius; "Oradaki evimizin civarnda Tifernum Tiberinum isminde bir kasaba var. Ben daha nerdeyse çocuk yaşta iken, oranın ahalisi, şeðk yönüyle aşırı, dirayet yönüyle de zayıf bir kararla beni koruyucuları (hamileri) olarak seçti. Kasabaya her gelişimi kutlarlar, ayrılışımdan üzüntü duyarlar, başarılarımdan da mutlu olurlar. Ben de buna karşıllk verebileyim diye (çünkü gösterilen sevginin altında kalmak insanı utandırır), kendi paramla bir tapınak inşa ettirdim" diyerek yanaşma bir kent ile hami arasındaki ilişki hakkında bilgi vermektedir (Plin. 4.1.4-5). Aynı kent, yıllar sonra aldıkları bir konsey kararı ile T. Pomponilus Bassus'a elçiler göndermiştir. Senatör olan T. Pomponilus Bassus ve ailesinin kentlerinin hamisi olmaları talebinde bulunmuşlardır. O da bu talebe olumlu cevap vermiştir. Q. Oppius ile Plarasa/Aphrodisias örneğinde olduğu gibi T. Pomponilus Bassus'a iletilen hamilik isteği benzerdir. Hamiyanaşma ilişkilerine ait önemli bilgiler veren başka kaynaklar ise tabulae patronatus adı verilen özel levhalardır (Eilers, 2002, s. 25-26).

Tabulae patronatuslar, Roma'da yanaşma kentler ile hamiler arasında gerçekleşen işbirliğinin esaslarını belirlemek amacıyla kullanılan çoğunlukla bronz levhalardır. Bu tabulae patronatuslar hami ve yanaşma ilişkileri için gerekli olan diplomatik adımların anlaşılması açısından önemlidir. Bunlar işbirliği kararnamelerinin bir kopyasını içermektedir. Aslında tabulae patronatuslar bir yabancı ile olan ilişkinin resmi olmayan kaydının tutulmasıdır. En erken tabulae patronatus muhtemelen M.Ö. II. yüzyılın ortalarına denk gelmektedir. Tabulae patronatusların kapsadığı coğrafi dağılım ağırlıklı olarak İspanya ile Kuzey Afrika'dır. Başlangıçta peregrin (yabancı) toplulukları için kullanılırken, daha sonra Romalılaşmış topluluklar için de kullanılmıştır. Tabulae patronatuslarda, onurlandırılan haminin statüsü eyaletten eyalete farkl1lıklar göstermektedir. Mesela İspanya'da 
Tarraconensis'te haminin bölgesel veya yerel bir öneme sahip olması gerekirken, Afrika'da ise genellikle emperyal öneme sahip bir görevli olması gerekliydi (Nicols\&Oreg, 1980, s. 537,559; Eilers, 2002, s. 26-27; Bloy, 2012, s. 180-181).

Bir kent yazılı bir anayasaya sahip değilse veya anayasasında özel olarak himayeyi düzenleyen bir madde olmasa bile talepte bulunmadan önce bazı özel adımlara ihtiyaç duyulduğu tahmin edilmektedir. Tabulae patronatusların geçerlilik kazanması için decretum decurionum, yani kent kararnameleri ile onaylanması gerekmekteydi. Hami seçiminin yapılabilmesi için gerekli olan kararname, kent konseyinin en az üçte ikisinin hazır bulunduğu toplantıda, yeminli olarak oylama yapılır ve çoğunluğun kararı ile kabul edilirdi. Bazı kentlerde halkın onayına da sunulmaktaydı. Bu kararnamenin bir kopyasını hami olarak seçilmiş olan kişiye sunmaları ve halkın isteğinin hami seçilen kişi tarafından kabulünü sağlamak için ordo decurionumdan (belediye meclisi) bu konuda yetkili olan elçiler seçilmekteydi. Hami olarak seçilen kişinin ne cevap verdiği ile ilgili olarak daha sonra işbirliğini kaydeden tabulae aenealar (veya patronatus) yazdırılmıştır. Bunlardan iki kopya yapılırdı. Biri haminin evine gönderilir, diğeri ise halka açık bir yere yerleştirilirdi (Gelzer, 1969, s. 87; Galsterer, 1988, s. 78-90; Nicols, 1989, s. 117-142).

$\mathrm{Bu}$ sözleşmelerin çoğunluğu hami-yanaşma sözleşmesi yapan kentin dişında bulunmuştur. İtalya'ya göre, M.S. I. yüzyılda İspanya'da Tarraconensis ve Africa Proconsularis'te daha fazla kullanıldığı anlaşılmaktadır. Çoğunluğu da kent halkları ile yapılan sözleşmelerdir. Pek çok decretum decurionumda (belediye meclisi tarafından çeşitli konularda çıarılan kararlar) olduğu gibi sözleşmelerin kayda geçirildiği tarih tabulae patronatusların başında görülmektedir. 30 tabulae patronatusun 26 'sında consullük yılı belirtilmektedir. Eksik olanların kararname olmadığı hamilerin halka karşı sorumluluklarının belirtildiği levhalar olduğu düşünülmektedir. Yıl belirtilen 26 tabulae patronatus da gün de belirtilmektedir. Tabulae patronatusların özelliği elçilerin oybirliği ile seçilmesi ve atamanın tamamlanması gerektiğidir. Bu özellik tabulae patronatusun sonunda özet olarak verilmektedir. Decretum decurionumun sunumu yapılmaktadır. Elçilerin isimleri bazen statüleri ve etnik kökenleri hakkında bilgi vermektedir (Nicols\&Oreg, 1980, s. 538-547; Eilers, 1999, s. 77-86).

Hem antik kaynaklardan hem epigrafik kaynaklardan toplulukların birden fazla hami seçebildikleri anlaşılmaktadır. Bu nedenle Cicero Capua kentinin tek hamisi olmaktan dolayı onur duyduğunu belirtmektedir. Hamilik statüsüne sahip olan seçkin aile mensuplarının içerisinde kadınlara da rastlanılmaktadır. Sayıları çok olmamakla beraber senatör statüsünde bulunan kadın hamiler bilinmektedir. Kadın hami ile ilgili bir örnek Stratonikeia kentinde bulunan bir yazıtta karşımıza çıkmaktadır. Yazıtta; "Proconsul Marcus Iunius Silanus'un kızı? Iunia? kentin hayırseveri ve atalardan kalma hamisi olarak halk tarafindan onurlandirlld ..." yazmaktadır (Eilers, C124; Cic. Pro Sest. 9; Nicols, 1989, s. 120-128; Gregory, 1997, s. 85-91).

Kentlerin özel gereksinimleri sayıları kadar çok olabiliyordu. Tabulae patronatus ve Q. Oppius'un cevabına bakarak bazı çıkarımlar yapılabilmektedir. İlk olarak muhtemelen kent ile hami arasında bazı ön anlaşmalar yapılmaktaydı. Öncelikle hami ile kent arasında karşılıklı bir sempatinin olması da gerekiyordu. Eğer hami talebi kabul etmiş ise bu karar yanaşma olacak kente iletilmekteydi. Kentler taleplerini ileri sürerken özel nedenlerini hamiye iletmek durumundaydılar. Bazı durumlarda Sicilya valiliği yapmış olan Gaius Verres gibi zorba bir valinin zulmünden kurtulmak için de hamilik talebinde bulunmuş olabiliyorlardı. Bu sayede hamilik yoluyla vali ile yakın bir bağ kurarak valinin zulmünden 
kurtulmayı ya da zulmünü hafifletmeyi umuyorlardı (Cic. Verr. 4; Ferrary, 1997, s. 112; Eilers, 2002, s. 27-28; Westbrook, 2005, s. 210-211).

Geç Cumhuriyet döneminde, birinin bir kentin hamisi olabilmesi için en yaygın fırsat o kişinin eyalet yöneticisi olduğu dönemdir. Bu duruma birçok örnek gösterilebilir. Söz gelimi L. Calpurnius Piso Caesoinus bunlardan biridir. Caesar'ın kayınpederi M.Ö. 57-55 yıllarında consullük yaptığı dönemde Makedonya'da üç kentin hamisi olmuştur. L. Antonius'un da M.Ö. 50 ile M.Ö. 49 yılında yöneticilik yaptığ1 Asia Eyaleti'nde birkaç kentin himayesini aldığını bilmekteyiz. Ona hamilik, muhtemelen yüksek vergi toplamadığı, onurlarını çiğnemediği ve onlardan daha fazlasını almadığı için minnettarlık olarak verilmiştir. Thyateira kentine ait bir yazıtta; "Halk Lucius Antoninus'un da hami ve hayırsever olarak onurlandırdı" yazmaktadır (L. Calpurnius Piso Beroeo, Eilers, C29; Samothrace, Eilers, C57; Amphipolis, Eilers, C 28 hamiliğini yaparken, L. Antonius Pergamum, Eilers, C72; Ephesus, Eilers, C86; Thyateira, Eilers, C104; kentlerinin hamiliğini yapmıştır (Eilers, 2002, s. 29; Nicols, 2014, s. 73).

M.Ö. 61-58 yılları arasında Asia Eyaleti proconsulü olarak görev yapan ünlü Q. Tullius Cicero'ya Kolophon kenti tarafından hamilik verilmiştir: "Halk Marcus'un oğlu proconsul Quintus Tullius Cicero'yu halkın hamisi ve Greklerin hayırseveri olarak onurlandırmıştır" (Eilers, C78; Tuchelt, 165). Q. Tullius Cicero'dan önce M.Ö. 62/61'de Asia Eyaleti yöneticiliği yapmış olan C. Valerius Flaccus adına da ayn kentin bir onurlandırma yazıtı bulunmaktadır. Yazıtta; "Halk proconsul Lucius'un oğlu Lucius Valerius Flaccus'un heykelini onlara karşı iyi ve yardımsever davrandığı ve kentimizin atalardan kalma hamisi olduğu için dikti" ibaresi yer almaktadır (Eilers, C81; Tuchelt, 164; Ferrary, 1997, s. 345-352).

Pompeius Magnus ise korsanlara ve VI. Mithridates'e karşı seferler düzenlediği dönemlerde birçok kentin hamisi olmuştur (Ionia Birliği, Eilers, C92; Tuchelt, 163; Ilium, Eilers, C66; Miletus, Eilers, C95; Tuchelt, 188; Side, Eilers, C146; Tuchelt, 240; Pompeipolis, Eilers, C149; Tuchelt, 235). Ionia Birliği'nin onurlandırma yazıtında; “Gnaeus'un oğlu imparator Gnaeus Pompeius'u Ionia birliği onurlandırdı. Karalarm ve denizlerin denetçisi Ionialılarm hamisi ve hayırseveri" yazmaktadır (Eilers, C92; Tuchelt, 163). Ancak Pharsalos Savaşı'ndan sonra birçok hamisi olduğu kent onu terk etmiştir. Ancak bazı kentler hamilik yükümlülükleri gereği ona yardımda bulunmak istemişlerdir. Bu konuda pek çok sıkıntıya rağmen sadakatte bulunan iki kent, Massilia ve Mytilene kentleri olmuştur. Elbette ki dönemin özelliği olarak Pompeius'un yenilgisi ve ardından ölümünden sonra Pompeius'a bağlı olan Hellen kentleri derhal Iulius Caesar'ın yanına yaklaşmışlardır. Caesar artık doğudaki pek çok Hellen kentinin hayırseveri ve hamisi olmuştur (Pergamum, Eilers, C74; Tuchelt, 208; Alabanda, Eilers, C106; Tuchelt, 135; Cnidos, Eilers, C115).

Pergamon yazıtında; "İmparator ve pontifex maximus, iki kez consul olan, Gaius'un oğlu Gaius Iulius Caesar'ı, tüm Greklerin hayırseveri ve kurtarıcısı, dindarllğı ve adaleti yüzünden halk onurlandırdı" yazmaktadır (Eilers, C74; Tuchelt, 208). Ephesos kenti ise Caesar'a adadığ1 yazıtta şöyle yazar: "Asia'nın kentleri, halkları ve kabileleri, yüce rahip ve iki kez consul olan, Ares ve insanlı̆̆ın kurtuluşunu sağlayacak Aphrodite'nin soyundan gelen Gaius'un oğlu, Gaius Iulius Caesar'ı onurlandırı"' (Syll 760; Freeman, 2019, s. 288).

Geç Cumhuriyet dönemi boyunca da Hellen kentlerinde hamilik sistemi devam etmiştir. Bu dönemde illerde hamilik yapan valilerin sayısal olarak, diğer hamiler arasında üstünlüğü barizdir. Bazı durumlarda komşu eyaletin yöneticisi olan kişilerin, diğer eyalete 
bağlı kentlerin hamiliğini yaptığı da görülmektedir (Cn. Cornelius Lentulus Marcellinus, Cyrene, Eilers, C162; M Pupius Piso Frugi, Miletus, Eilers, C96; Samos, Eilers, C54; Q. Murcius, Scavola ve Qeoanda, Eilers, C131; M. Aemilius, Lepidus ve Myra, Eilers, C129; Eilers, 2002, s. 29-30; Lintott, 2010, s. 70-75; Nicols, 2014, s. 73-74).

Yukarıdaki örneğimiz de olduğu gibi, Q. Oppius aslında Kilikia Eyaleti'nin yöneticisiydi ama Karia kenti olan Plarasa/Aphrodisias'ın hamisiydi. Muhtemelen işbirliği olduğu zaman sınır sorun olmaktan çıkıyordu (Reynolds, doc. 3; Broughton, 1952, s. 42). Olağanüstü durumlarda da bazı Romalıların sürgünde olmalarına rağmen bulundukları bölgede hamilik yaptıkları da bilinmektedir (Eilers, 2002, s. 30; P. Glitius Gallus, Andros, Eilers, C32; L. Caninius Gallus, Thespiae, Eilers, C24; M. Claudius Marcellus, Delphi, Eilers, C13; Syll 774a ve Tanagra, Eilers, C23; Syll 774b). Örneğin Adriyatik'in karşısında yer alan Dyrrachium kenti Cicero'yu, sürgüne gidişinde onu fidesi olarak kabul etmiştir (Deniaux, 2006, s. 406; Bloy, 2012, s. 177).

Kentlerin hamiliği ile ilgili olarak farklı usullerde hamilik sistemi görülebilmekteydi. İlk olarak Plarasa/Aphrodisias yazıtında olduğu gibi (Reynolds, doc. 3) gönüllülük esasına dayanmaktadır. İkincisi ise istemsiz olarak oluşturulan hamilikti. Aslında bireylerle ilgili olan hamilikte de bunu görebilmekteyiz. Özgür bireylerin hamiliği gönüllülük esasına dayanırken, azatlı kölelerin (libertus) hamiliği ise kendilerine göre istemsizdi. Kentlerin istemsiz hamilikleri, fetih yoluyla sağlanan hamilik veya sömürge yoluyla, koloni oluşturmak için sağlanan hamilik olarak belirtilebilir (Eilers, 2002, s. 34-36; Deniaux, 2006, s. 406; Bloy, 2012, s. 170; Nicols, 2014, s. 4).

Roma'da yaygın olarak uygulanan bir gelenek de Romalı generallerin fethettikleri kentlerin hamileri olmaları idi. Bu uygulama Geç Cumhuriyet dönemine kadar devam etmiştir. Fetih yoluyla himaye konusundaki bilgilere özellikle Cicero'nun De Officiis adlı eserinde ulaşmaktayız. Cicero Romalı komutanların mağlup ettiği düşmanın topraklarının hamisi olması gerektiği belirtmektedir. Bu hamiliğin miras yoluyla da devam etmesinin gerekliliğinden bahseder (Cic. De. Off. I. 35; Nicols, 1990b, s. 101; s. 156; Eilers, 2002, s. 38; Deniaux, 2006, s. 405; Bloy, 2012, s. 169).

Cicero De Officiis I. 35'te; savaş konusunu anlattığı pasajında fetih yoluyla hamilik sistemi hakkında bilgi vermektedir: "Belirli görevlerin meydana gelmesinde günahkârlara bile borçluyuz. Özellikle suçlarından pişman olmaları ve tekrar etmemeleri öğretilmelidir. Bu ilke savaş ahlakının çerçevesini sunmaktadır. Savaşın gerekçesi barışı sağlamaktadır. Savaşlar adaletsizlik olmadan huzur içinde yaşayabilmek için yapılmalıdır. Zafer kazanıldıktan sonra savaşta acımasız ve zalim olmayan korunmalıdır. Bu nedenle mağlup olmuş İtalyan halklar bağışlanmalı ve Roma vatandaşı olmalı. Kartaca ve Numantia kentleri zulümleri nedeniyle yok edilmiştir. Savaş ancak barışı desteklediğinde haklıdır. Fetih gönüllü olarak teslim olanlar veya zorla fethedilenleri korumalıdır". Roma geleneği olarak fethedilenlerin himaye altına alınması, Roma'nın halk tarafından büyük saygı duymasına neden olmuştur. Cicero'nun fetih yoluyla hamilik hakkında verdiği bu bilgiler eşsizdir (Cic. De Off. I. 35; Eilers, 2002, s. 38-41).

Roma cumhuriyet döneminde, Romalı generaller genelde fethettikleri toprakların hamileri olmuşlardır. Koloni kurucuları olanlar ise en azından Cumhuriyet'in sonuna kadar bu kolonilerin hamiliklerini sürdürmüşlerdir. Fetih yoluyla hamilik örneklerinden biri de Claudius Marcellus ve Syrakousai kenti arasındaki ilişkidir. Cicero'nun, Claudius 
Marcellus'u Syrakousai'nin ve diğer Sicilya kasabalarının hamisi olarak gördüğü pasajlarından anlaşılmaktadır (Cic. Verr. 2.3-2. 4; Plut. Marc. 23) .

$\mathrm{Bu}$ hamilik ilişkisinin, II. Kartaca Savaşı'ndan sonra Marcellus'un Sicilya'daki seferlerinden kaynaklandığ kabul edilmektedir. Ancak Livius, Marcellus'un Syrakousai'nin doğrudan hamisi olduğu görüşünü kabul etmemektedir (Liv. 26. 32; Braund, 1990, s. 139-140; Eilers, 2002, s. 61; Deniaux, 2006, s. 405; Bloy, 2012, s. 172).

Roma makamlarına erişmenin en sağlam yollarından biri olarak, talepleri doğrultusunda hamileri olan seçkin aileler kuşaklar boyu kentlerin hamiliğini devam ettirebiliyorlardı. Seçkin ailelere sahip Romalılar için mümkün olduğu kadar çok yanaşmaya sahip olmak büyük bir itibar meselesiydi. Genelde her iki taraf hami-yanaşma ilişkisini devam ettirerek atalardan kalan bu mirasın avantajlarını korumaya çalışıyorlardı. Tabulae patronatuslar bu mirasın devamı ile ilgili bilgiler vermektedir. M.Ö. 50 ile M.S. 250 yılları arasında bu tür ilişkilerin devamına dair 30 tabulae patronatus bize bilgi vermektedir (Badian, 1967, s. 163-164; Nicols, 1980, s. 367; s. 542; Ferrary, 1997, s. 108; Eilers, 2002, s. 62-63).

Hamilik genelde doğrudan haminin ölümünden sonra onun neslinden gelen seçkin bir bireyle devam edebiliyordu. Ancak bazı durumlarda hamiliğin miras olarak devam etmediği de görülmektedir. Hellence ve Latince yazıtlarda yaklaşık 1500 kentin hamiliğini yapan isimlere rastlanmaktadır. Bu örneklerde baba ile oğulun birlikte isimlerinin bulunduğu yazıtlarda mevcuttur. Bazen ilişki birkaç kuşak devam edebiliyordu. Ancak hem yanaşma olan kent hem de haminin oğlu ilişkinin devamını reddedebiliyordu. Ya da Lex Ursonensis (koloni yasası) örneğinde olduğu gibi haminin çocukları ve torunları hamilik ilişkisini devam ettirebiliyorlardı. Ama bu ilişkinin devamı için, kent konseyinin oy çokluğu ile oylama yapması gerekiyordu. Hatta bazen halk oylamasının da yapılması gerekebiliyordu (Eilers, 2002, s. 68-82; Bloy, 2012, s. 171).

Bu konuda M. Acilius Glabrio'nun yazmış olduğu mektuplar da vardır. M.Ö. 191'de Yunanistan'da komutanlık görevi yaptığı dönemde, Delphoi'yi Aitalia'lılardan kurtarmıştır. "Baştan beri var olan atalarmızın hakların, yalnız size ait olduğunu ve kentin ve tapınağın özerkliğinin korunmasını sağlamak için tüm gücümle Roma'da çalışacağım" diye söz vermektedir (Syll 609; Ager, 239; Sherk, 221-224).

Bu yazıtın $Q$ Oppius yazıtı ile içerik bakımından benzerliği dikkat çekmektedir. Delphoi kenti bahsedilen hakları sağlamıştır. Ancak üç elçi Roma dönüş yolunda öldürülmüştür. Söz konusu yazıt kent hamiliğinin miras yoluyla devam ettiğini gösteren yazitlardan bir tanesidir. Atalardan kalma hamilik nedeniyle Hellen kentlerinin Romalı hamileri onurlandırdığı çok sayıda yazıt bilinmektedir. Bunlardan biri olan Ephesos kentinin Domitius Ahenobarbus'un adına adadığı hamilik yazıtıdır. Yazıtta; "Imparator Gnaeus Domitius Ahenobarbus kentin ve Artemis Tapınağı'nın atalardan kalma hamisidir" yazmaktadır (Eilers, C88; Tuchelt, 143).

Domitius Ahenobarbus triumvirlik döneminde doğuda Brutus'ü destekleyen önemli bir aktördü. Bir süre bağımsız hareket ettikten sonra Marcus Antonius'a katıldı. Nihayet Actium Savaşı'ndan önce de Octavianus'a katıldı. Bundan kısa bir süre sonra da öldü. Yazıtta kentin atalardan kalma hamisi olarak adlandırılır. Tıpkı Samos'ta olduğu gibi (Eilers, C52) ilişkinin kökeni büyük dedesi Domitius Ahenobarbus'a dayanmaktadır. M. Aquillius

SEFAD, 2020; (44): 527-546 
döneminde propraetor olarak görev yapmıştır. Kendisi hakkında Samos'ta bir yazıtta, "senatus tarafindan verilen hamilik" ibaresi yer almaktadır (IG XII/6. 351; Eilers, C51).

Ayrıca L. Domitius Ahenobarbus da M.Ö. 54 yılında consul olduğu dönemde Khios (Eilers, C37) ve Miletos (Eilers, C93; Tuchelt, 190) tarafından hami olarak onurlandırılmıştır. Onun babası Ephesos ve Samos'un atalardan kalma hamisi olmuştur. Bu doğrultuda Ephesos'un ve Samos'un, Khios ve Miletos ile ayn zamanda kendilerinin hamisi olarak seçtiklerini söylemek gerekir. Oğlunun da bu ilişkileri devam ettirdiğini belirtmek doğru olur. Bir oğulun babasının yerine hami olabilmesi için ancak kendisinin aile reisi (pater familias) olduğu zaman mümkün olabiliyordu. Lex Ursonensise göre kişinin hami olabilmesi için onların neslinden de gelmesi gerekmekteydi (Bloy, 2012, s. 177-180; Eilers, C52; Eilers, C59; Eilers, C81; Eilers, C88; Eilers, C103; Eilers, C105; Eilers, C110; Eilers, C112; Eilers, C116; Eilers, C121; Eilers, C124; Cic. Flac. 53 = Eilers, C125-6; Crawford, I 25; Reynolds, doc.3; Ager, 239; Sherk, 221-224)

Mahkemelerde sanıkların temsilcilerine de, davasını savunan adam olarak hami denilmekteydi. Aslında her iki durumda da işlev aynıdır. Himaye her zaman zayıf tarafın korunması anlamına geliyordu. Kamuyu ya da bireyleri ilgilendiren önemli davalara çoğunlukla, hâkimler senatus tarafından atanırdı. Polybios bu durumu senatusun insanlar üzerindeki kontrolünde önemli bir faktör olarak görmektedir. Ona göre insanlar senatörlerin iyi niyetine güvenmek zorunda kalmışlardır (Polyb. 6. 17). C. Gracchus M.Ö. 122'de en önemli değişikliği mahkeme/soruşturma reformu ile bu yetkiyi equiteslere (üst düzey sınıf/atlı sinif) devretmiştir. Daha sonra Sulla bu yetkiyi M.Ö. 81'de senatusa geri vermiştir (Gelzer, 1969, s. 70-72; Deniaux, 2006, s. 402-408).

Roma'da zamanla savunma görevi bir meslek haline gelmiştir. Kentte iş takibi erken saatlerde başlardı. Etkin olabilecek aristokrat kişilere ulaşılır ve onları selamlama (salutatio) yapılırdı. İşler için çoğu zaman en etkin saatler öğle saatlerinde olurdu. Hatta hamiler, yanaşmalarına evlerinin bahçelerini açtıklarında coşkulu bir selamlama (salutatio) düzenlenirdi. Böylece yanaşmalar onlara itibar gösterirler ve hatta onlara fiziki bir koruma sağlamış olurlardı. Cumhuriyet'in başlarında aslında haminin mahkemelerde savunmacı özelliğinden daha çok yanaşmalarına yasal konularda danışmanlık yapması işlevseldi (Gelzer, 1969, s. 89; Zvi, 1969, s. 60; Lintott, 1999, s. 158; 2010, s. 152; Deniaux, 2006, s. 407411).

M.S. I. ve II. yüzyılda doğuda pek çok Hellen kenti Roma İmparatorluğu'nun himayesine girmiştir. İmparator Augustus da pater patriae (vatanın babası) unvanıla pek çok kentin hamiliğini yapmıştır. Ilium (Troia) kentine ait İmparator Caesar Augustus adına bir onurlandırma yazıtı bulunmaktadır. Yazıtta; "Iliumlular ve dini törenlerine ve oyunlarına iştirak eden kentler tarafindan tanrinın oğlu, Imparator Caesar Augustus'u herkesin hayırseveri ve kentlerin kurtarıcısı ve hamisi ve akrabası/soydaşı olarak onurlandırdı" yazmaktadır (Eilers, C64). Augustus Ilium vatandaşlarının hamisiydi fakat oyunlara katılan diğer kentlerin muhtemelen hamisi değildi. Augustus'a yazıtta akraba/soydaş tabirinin kullanılması, muhtemelen kendilerini Toria'dan gelen Aeneas'in soyundan geldiklerini ima etmekteydiler. Augustus'un ayrıca Plataia kenti (Eilers, C22) ile birlikte başka kentlerin de hamisi olduğu bilinmektedir (Zvi, 1969, s. 152-153; Nicols, 1990a, s. 81-100; 1990b, s. 102; Lintott, 2010, s. 100). 


\section{SONUÇ}

Karşlıklı çıar ilişkisine dayanan patronus-cliens ilişkisi, özellikle Hellen kentleri açısından Roma hâkimiyet alanında varlıklarının devamı için vazgeçilmez olmuştur. Himaye sistemi Hellen ve Roma dünyasının temel konularından biri olmuştur. Patronus(hami)-cliens(yanaşma) ilişkisi Roma'da kişisel bir ilişki olarak görülürken daha sonra Roma'nın gücünün etkisiyle Romalı soylular ile değişik eyaletlerde bulanan kentler arasında bu ilişki yaygınlaşmıştır. Hami-yanaşma ilişkisi resmi bir ilişki türü değildir. Yani tarafların sorumluluklarını yerine getirmedikleri takdirde hukuki bir yaptırımı söz konusu değildir. Ahlâki temelli bir ilişki türüdür. Kişisel hami-yanaşma ilişkisinde soylular değerli gördükleri sanatçıları ya da azatlı kölelerini himayeleri altına almışlardır. Bu sistem daha yaygın olarak kentlerle Romalı seçkin üst düzey yöneticiler arasında görülmektedir.

Küçük Asia'daki Hellen kentleri Roma senatusu ile olan ilişkilerini daha hızlı ve etkin şekilde sürdürebilmek için, senatusda sözü geçen kişilerin himayesine girmeyi tercih etmişlerdir. Yanaşma olan kentler hamisi adına onurlandırma yazıtları yazdırmışlardır. Onlara karşı olan maddi veya diğer yükümlülüklerini yerine getirmeye çalışmışlardır. Böylece halkın yaşamını daha da kolaylaştırmaya çalışmışlardır. Hamiler açısından ise bu ilişkinin maddi boyutundan daha önemlisi itibarlarının artmasıydı. Çünkü hamilerin ne kadar çok himayesi altında kent olursa, itibarları da o kadar artmaktaydı.

Bir diğer tür hami-yanaşma ilişkisi olarak, Romalı generallerin fethettikleri toprakları himayesi altına almalarını görmekteyiz. Kimi zaman bu hami-yanaşma ilişkisi miras olarak atalardan kalabiliyordu. Her iki tarafında isteği doğrultusunda bu bağ nesiller boyu devam edebiliyordu. Küçük Asia'daki Hellen kentleri tarih açısından değerli kayıtlara sahiptir. Bu ilişkinin varlığı ile ilgili değişik kentlere ait pek çok yazıt mevcuttur. Bu sayede Hellen kentlerinin belirli dönemleri ile ilgili, özellikle Roma ile olan ilişkileri hakkında bilgi sahibi olabilmekteyiz.

\section{SUMMARY}

It is a special type of relationship between Patronus, that is to say, patron, and cliens, i.e client. Such a loyalty-based relationship is observed between the freedman and his master in Rome. Alternatively, this kind of relationship can be observed between a distinguished Roman and some artists. However, it is more commonly observed between the cities and a noble Roman.

Also observed in the Western Anatolia Hellenic cities during Hellenistic and Roman periods, patronus-cliens relationship contains detailed information about the diplomatic and political structures of that era's cities. It was used as an effective tool in the regulation of relationships with Roman senatus in the Hellenic cities. The existence of such a relationship is observed in the regulation of the relationships with senatus, in the solution of a problem or, to say the least, not to face heavy taxes and conditions by the managers. The cities needed to choose a patron for themselves to ensure their connections with Roman senatus more easily. They honored their patrons, who accepted them as clients, through various inscriptions. They stated their loyalties in this way. There is no legal basis for the relationship of patron-client. It is a relationship based entirely on moral principles. Therefore, any legal sanction is not in question. To facilitate the solution of their problems with the Roman senatus, the cities chose an influential character in senatus as their patron. It is understood that the noble, who was the

SEFAD, 2020; (44): 527-546 
patron, benefited from this situation mainly in terms of reputation. Because, the more the patron had clients, the more his reputation in Rome increased.

Western Anatolia Hellenic cities used many terms meaning as philanthropists or protectors of cities, before the Roman period. The terms such as Euergetes, benefactor, soter, kedemon and proxenos, which have similar meanings, can be seen in many inscriptions. With the intensification of diplomatic relations with Rome, they chose a Roman person as patronus, that is to say, patron for themselves. The document providing the clearest and detailed information about how this relationship started, is coming from the city of Plarasa/Aphrodisias in Karia. The Asia State in Laodicea belongs to Q. Oppius, its proconsul. The people of the city of Plarasa/Aphrodisias, who responded to his call for support in a short time during the Mithridates Wars, offered to Q. Oppius to become their patron after the war. Q. Oppius, on the other hand, responded positively to this proposal by a letter. This letter belonging to $\mathrm{Q}$. Oppius contains important information about the relationship of patronus-cliens.

In the patronus-cliens relationship of the cities, which was based on mutual volunteerism, the demand generally comes from the cities that desired to be cliens, that is to say client. There is no legal sanction of this relationship between patronus, that is to say the patron, who accepted to be the patron and patronized the cities, and the client. It is a relationship based entirely on a moral foundation. These relationships could sometimes keep going for generations. In other words, this relationship, which was inherited from the ancestors, could keep going provided that both sides agreed on it.

The other sources providing substantial information about the patron-client relationships are special plates called as tabulae patronatus. Tabulae patronatus are generally bronze plates used to determine the principles of cooperation between cliens cities and patrons in Rome. These tabulae patronatus are important in terms of understanding the diplomatic steps required for patron and client relationships. These include a copy of the decrees of cooperation. Tabulae patronatus is the unofficial recording of the relationship with a stranger. Besides the inscriptions and plates, antique sources also provide important information about the relationship of patronus-cliens between Rome and the cities under the influence of its power. 
Makale Bilgileri

Etik Kurul Kararı: Etik Kurul Kararından muaftır.

Katılımcı Rızası: Katılımci Yok

Mali Destek: Çalışma için herhangi bir kurum ve projeden mali destek alınmamıştır.

Çıkar Çatışması: Çalışmada kişiler ve kurumlar arası çıkar çatışması bulunmamaktadır.

Telif Haklart: Telif hakkına sebep olacak bir materyal kullanılmamıştır.

Article Information

Ethics Committee Approval: Exempt from the Ethics Committee Decision.

Informed Consent:

No participant

Financial Support:

No financial support from any institution or project.

Conflict of Interest:

No conflict of interest.

Copyrights:

No material subject to copyright is included. 


\section{KAYNAKÇA}

Ager, L. S. (1997). Interstate Arbitrations In the Greek World, 337-90 B.C. Berkeley-Los AngelesOxford: University of California Press.

Akderin, F. (2018). Latince Sözlük. İstanbul: Say Yayınları.

Badian, E. (1967). Foreign Clientelae (264-70 BC). Oxford: Clarendon Press.

Bloy, D. (2012). Roman Patrons of Greek Communities Before the Title... . Historia: Zeitschrift für Alte Geschichte, 61(2), 168-201. Erişim adresi: https://www.jstor.org/action/doBasicSearch?Query=Roman+Patrons+of+Greek+Commu nities+Before+the+Title.

Bowersock, G. W. (1965). Augustus and The Greek World. Oxford: Clarendon Press.

Braund, D. (1990). Function and dysfunction: personal patronage in Roman Imperialism. A. Wallace Hadrill (Ed.), Patronage in Ancient Society (s. 137-152). London: Routledge.

Broughton, T.R.S. (1952). The Magistrates of The Roman Republic II. New York: American Philological Association.

Cambridge: Cambridge University Press.

Cicero (1916). Against Verres. The Orations of Marcus Tullius Cicero I (C. D. Yonge,

Cicero (1919). Letters to Atticus (E. O. Winstedt, M. A, Trans.). London-New York:

Cicero (1928). De Officiis (W. Miller, Trans.). London-New York: William Heineman

Cicero (1958). Pro Sestio. Orations, Pro Sestio In Vatinium (R. Gardner, Trans.).

Cicero (1976). Orations, In Catilinam 1-4: Pro Murena-Pro Sulla, Pro Flacco (C. Macdonald,

Crawford, M. H. (1996). Roman Statutes I. London: Institute of Classical Studies.

Deniaux, E. (2006). Patronage. N. Rosentein \& R. Morstein (Ed.), A Companion to the Roman Republic (s. 401-420). Malden-Oxford-Victoria: Wiley-Blackwell.

Eilers, C. C. (1991). Cn. Domitius and Samos: A New Extortion Trial. ZPE, 89, 167-178. Erişimadresi:https://www.jstor.org/action/doBasicSearch?Query=Cn.+Domitius+and+Sa mos.

Eilers, C. C. (1999). M. Silanus, Stratoniceia, and the Governors of Asia under Agustus. Tyche, 14, 77-86. Erişim adresi: https://tyche-journal. at/tyche/index.php/tyche/article.

Eilers, C. C. (2002). Roman Patrons of Greek Cities. Oxford: Oxford University Press.

Emiroğlu, K \& Aydın, S. (2003). Antropoloji Sözlüğ̈̈. Ankara: Bilim ve Sanat Yayınları.

Ferrary, J. L. (1997). The Hellenistic World and Roman Political Patronage. P. Cartledge \& P. Garnsey \& E. Gruer (Ed.), Hellenistic Constructs Essays in Culture, History and Historigraphy (s. 105-119). Berkeley-Los Angeles-London: University of California Press.

Finley, M. I. (1983). Politics in The Ancient World. Cambridge: Cambridge University Press.

Freeman, P. (2019). Iulius Caesar (Ü. E. Uysal, Çev.). İstanbul: Kronik Kitap.

G.P. Putnam's Sons.

Galsterer, H. (1988). Municipium Flavium Irnitanum: A Latin Town in Spain, JRS, 78, 78-90. Erişim adresi:https://www.jstor.org/action/doBasicSearch?Query=Municipium.

Garnsey, P. \& Woolf, G. (1990). Patronage of the rural poor in the Roman World. A. Wallace Hadrill (Ed.), Patronage in Ancient Society (s. 153-170). London: Routledge.

Gelzer, M. (1969). The Roman Nobility (R. Seager, Trans.). Oxford: Basil Blackwell. 
Gregory, A. P. (1997). A New and Some Overlooked Patrons of Greek Cities In the Early Principate, Tyche, 12, 85-91. Erişim adresi: https://tyche journal.at/tyche/index.

Herman, G. (1987). Ritualised Friendship \& The Greek City. Cambridge: Cambridge University Press.

Herodotos (2002). Herodot Tarihi (M. Ökmen, Çev.). İstanbul: Türkiye İş Bankası Kültür Yayınları.

Herrmann, P. (1974). Cn. Domitius Ahenobarbus: Patrons von Ephesos und Samos, ZPE, 14, 257-258. Erişim adresi: https://www.jstor.org/stable/20180702?seq=1\#metadata.

Inscriptiones Graecae. Erişim adresi http://telota.bbaw.de/ig/IG\%20XII\%206,\%201,\%20351?qString=351. Erişim tarihi: $14 / 10 / 2019$.

Johnson, T. \& Dandeker, C. (1990). Patronage: relation and system. A. Wallace Hadrill. (Ed.), Patronage in Ancient Society (s. 219-242). London: Routledge.

Karahan, Ü. O. (2019). Hellenistik ve Roma Dönemi'nde Hellen Kentlerinde Tahkim: SamosPriene Örneği. History Studies, 11(3), 963-981. DOI Number: 10.9737/hist.2019.749

Lintott, A. (1999). The Constitution of the Roman Republic. Oxford: Clarendon Press.

Lintott, A. (2010). The Romas in the Age of Agustus. Malden-Oxford: Wiley-Blackwell.

Nicols, J \& Oreg, E. (1980). Tabulae Patronatus: A study of the Agreement between Patron and Client Comunity. T. Hildegard-Haase (Ed.), ANRW / Geschichte und Kultur Roms I m Spiegel Der Neueren Forschung (s. 535-561). Berlin: Wolfgang.

Nicols, J. (1980). Pliny and The Patronage of Communities. Hermes, 3, 365-385. Erişim adresi:https://www.jstor.org/action/doBasicSearch?Query=Pliny+and+The+Patronage+o $\mathrm{f}+$ Communities.

Nicols, J. (1989). Patrona Duitatis: Gender and Civic Patronage. C. Deroux (Ed.), Studies in Latin Literatüre and Roman History V (s. 117-142). Bruxelles: Latomus.

Nicols, J. (1990a). Patrons of Greek Cities in the Early Principate. ZEP,80, 81-100. Erişim adresi: https://www.jstor.org/action/doBasicSearch?Query=Patrons+of+Greek.

Nicols, J. (1990b). Patrons of Provinces in the Early Principate: The Case of Bithynia. ZEP 80. 101-108. Erişim adresi: https://www.jstor.org/action/doBasicSearch?Query.

Nicols, J. (2014). Civic Patronage in the Roman Empire. Leiden-Boston: Brill.

Plinius (2018). Genç Plinius'un Mektupları (L. Keskin, Çev.). Ankara: Doğu Batı Yayınları.

Plutarkhos (1955). Bio Paralleoi. Plutarch's Lives V (B. Perrin, Trans.). Cambridge-London: Harvard University Press-William Heinemann Ltd.

Plutarkhos (1959). Bio Paralleoi. Plutarch's Lives VIII (B. Perrin, Trans.). Cambridge-London: Harvard University Press-William Heinemann Ltd.

Polybios. (1957). The Histories. A Historical Commentary on Polybius I (F.W. Walbank, Trans.). Oxford: Clarendon Press.

Polybios. (1967). The Histories. A Historical Commentary on Polybius II (F.W. Walbank, Trans.). Oxford: Clarendon Press.

Polybios. (1979). The Histories. A Historical Commentary on Polybius III (F.W. Walbank, Trans.). Oxford: Clarendon Press.

Pomeroy, S. B. (2018). Antik Yunan'ın Kısa Tarihi (O. Yarlıgaş, Çev.). İstanbul: Alfa. 
Reynolds, J. (1982). Aphrodisias and Rome. London: Society for the Promotion of Roman Studies.

Rich, J. (1990). Patronage and Interstate Relations in the Roman Republic. A. Wallace Hadrill (Ed.), Patronage in Ancient Society (s. 117-135). London: Routledge.

Saller, R. P. (1982). Personal Patronage under The Early Empire. Cambridge: Cambridge University Press.

Sherk, R. K. (1969). Roman Documents From The Greek East. Baltimore: The Johns Hopkins University Press.

Sylloge Inscriptionum Graecarum. Erişim adresi: http://www.attalus.org/docs/sig.html. Erişim tarihi: 14/10/2019.

Tacitus (1980). The Histories. I- III (C. H. Moore, Trans.). Cambridge-London: Clarendon Press.

Tekin, O. (2012). Eski Yunan ve Roma Tarihine Giriş. İstanbul: İletişim Yayınları.

Titus Livius (1943). History of Rome. Livy VII From The Founding of The City (F. G. Moore, Trans.). London-Cambridge: Harvard University Press-William Heinemann.

Titus Livius (2007). History of Rome. Rome's Mediterranean Empire. Books 41-45 and the Periochae (J. D. Chaplin, Trans.). Oxford: Oxford University Press.

Trans.). Cambridge: Cambridge University Press.

Trans.). London: Richard Clay.

Tuchelt, K. (1979). Frühe Denkmäler Roms in Kleinasien. Teil I. Roma und Promagistrate. Tübingen: Wasmuth.

Valerius Maximus (1684). Memorable Acts and Sayings. Collections of the Memorable Acts and Sayings (B. Crayle, Trans.). London: Benjamin Crayle.

Wallace Hadrill, A. (1990). Patronage in Roman Society: from republic to Empire. A. Wallace Hadrill (Ed.), Patronage in Ancient Society (s. 63-87). London: Routledge.

Wallace, M. B. (1970). Early Greek Proxenoi. Phoenix, 24(3), 189-208. Erişim adresi: https://www.jstor.org/action/doBasicSearch?Query=Early+Greek+Proxenoi

Westbrook, R. (2005). Patronage in the Ancient Near East. Journal of the Economic and Social History of the Orient, 48(2), 210-233. Erişim adresi: https://www.jstor.org/action/doBasicSearch?Query=Patronage

William Heineman-G.P. Putnam's Sons.

Zvi, Y. (1969). Plebs and Princeps. Oxford: Clarendon Press. 